\title{
Molecular Dynamics Simulation Study of Carbon Dioxide, Methane, and Their Mixture in the Presence of Brine
}

Yafan Yang, Arun Kumar Narayanan Nair, and Shuyu Sun Physical Science and Engineering Division (PSE), Computational Transport Phenomena Laboratory, King Abdullah University of Science and Technology (KAUST), Thuwal, 23955-6900, Saudi Arabia.

October 3, 2017

\footnotetext{
*To whom correspondence should be addressed, email: arun.narayanannair@kaust.edu.sa
} 


\begin{abstract}
We perform molecular dynamics simulations to study $\mathrm{CO}_{2}$, methane, and their mixture in the presence of brine over a broad range of temperature (311$473 \mathrm{~K}$ ), pressure (up to about $100 \mathrm{MPa}$ ), and $\mathrm{NaCl}$ concentration (up to about $14 \mathrm{wt} \%$ ). The general decrease in the interfacial tension (IFT) values of the $\mathrm{CH}_{4}$-brine system with pressure and temperature is similar to that obtained for the corresponding $\mathrm{CH}_{4}$-water system. The IFT of methane and brine is a linearly increasing function of salt concentration, and the resulting slopes are dependent on the pressure. A similar behavior as methane is observed for such systems containing $\mathrm{CO}_{2}$ and $\mathrm{CO}_{2}-\mathrm{CH}_{4}$ mixture. The IFT of $\mathrm{CO}_{2}$ and brine increases linearly with increasing salt content, however, the resulting slopes are independent of pressure. The simulations show that the presence of $\mathrm{CO}_{2}$ decreases the IFT values of the $\mathrm{CH}_{4}$-water and $\mathrm{CH}_{4}$-brine systems, while the degree of reduction depends on the amount of $\mathrm{CO}_{2}$ in each sample which is consistent with experimental evidence. These IFT values show a linear correlation with the amount of $\mathrm{CO}_{2}$, and the resulting slopes are dependent on temperature and pressure. Furthermore, our results for the mole fractions of the different species in the $\mathrm{CO}_{2}-\mathrm{CH}_{4}$-water system at $323 \mathrm{~K}$ and $9 \mathrm{MPa}$ are in agreement with experiments. The mole fractions of methane and $\mathrm{CO}_{2}$ in the water-rich phase decrease with increasing salt concentration, while that of $\mathrm{H}_{2} \mathrm{O}$ in the methaneor $\mathrm{CO}_{2}$-rich phases remains almost unaffected in all studied cases. Our results could be useful because of the importance of carbon dioxide sequestration and shale gas production.
\end{abstract}




\section{Introduction}

Geologic storage of carbon dioxide offers a promising means of reducing emissions of anthropogenic $\mathrm{CO}_{2}$ into the atmosphere. ${ }^{1-5}$ One unique approach to reducing emissions involves utilizing $\mathrm{CO}_{2}$ for the extraction of oil and gas from shale formations. ${ }^{1,4}$ Typically carbon dioxide has a higher affinity for the shale formations and will therefore displace adsorbed $\mathrm{CH}_{4}$. The detailed information of interactions between methane, $\mathrm{CO}_{2}$, aqueous brine, and shale formations is required in simulators during natural gas production. For example, relative humidity could affect sorption of methane and carbon dioxide onto both organic and inorganic components of shales. ${ }^{1,3,5-7}$ The extent to which shale formations rich in expandable clays such as the smectite mineral montmorillonite swell is controlled primarily by the $\mathrm{H}_{2} \mathrm{O}$ concentrations in the contact fluid. Swelling due to $\mathrm{H}_{2} \mathrm{O}$ intercalation processes could lead to permeability changes that directly impact successful storage of $\mathrm{CO}_{2}$. Therefore the knowledge of the dissolved $\mathrm{H}_{2} \mathrm{O}$ concentrations in contact fluids ${ }^{8}$ can help develop rational injection strategies to maximize geological $\mathrm{CO}_{2}$ storage and natural gas production. Interfacial tension (IFT) is a property of great significance to $\mathrm{CO}_{2}$ sequestration, because it controlls capillary forces in the cap rock which act to avoid upward migration of the stored fluid. ${ }^{9,10}$ In the $\mathrm{CO}_{2}$-enhanced oil recovery processes, information must be obtained on important properties of the participating fluid mixtures. ${ }^{11,12}$ The study of interactions between $\mathrm{CO}_{2}$ and water is important as a reference point for the understanding of a large variety of interfacial processes, for instance, those including surfactants. ${ }^{13,14}$

A number of experimental, ${ }^{15-19}$ theoretical, ${ }^{19-21}$ and simulation ${ }^{21-23}$ studies have been carried out to determine the interfacial properties of $\mathrm{CH}_{4}$-water and $\mathrm{CH}_{4}$-brine systems. In general, the results of these studies showed a reduction of the IFT with increasing pressure. However, at relatively high pressures the IFT values exhibited a moderate increase with increasing pressures. ${ }^{16,19,21}$ The inversion of the IFT dependence with pressure and the observation of an IFT minimum occurred for pressures around the transition point between the positive and negative relative adsorption of 
methane molecules with respect to water molecules in the interfacial region. ${ }^{19,21}$ The density gradient theory (DGT) was able to predict the measured increase of the IFT of the methane-water system due to the presence of up to $10 \mathrm{wt} \% \mathrm{NaCl}{ }^{19}$ Several experimental, ${ }^{15,24-33}$ theoretical, ${ }^{28,31,33-37}$ and simulation ${ }^{24,37-44}$ studies have also been performed to determine the interfacial properties of $\mathrm{CO}_{2}$-water and $\mathrm{CO}_{2}$-brine systems. Overall, IFT decreased with both temperature and pressure in the low-pressure range (gaseous $\mathrm{CO}_{2}$ ) but was mostly independent of pressure at high pressures (liquid or supercritical $\mathrm{CO}_{2}$ ). The results of these studies also indicated that the IFT increases linearly with the molality (or ionic strength) of the salt solution. ${ }^{26,30,33,41,43}$

Only few experimental, ${ }^{18,45}$ theoretical, ${ }^{37}$ and simulation ${ }^{37}$ studies have addressed interfacial properties of $\mathrm{CO}_{2}-\mathrm{CH}_{4}$-water and $\mathrm{CO}_{2}-\mathrm{CH}_{4}$-brine systems. Ren et al. ${ }^{18}$ reported the IFT of $\mathrm{CO}_{2}-\mathrm{CH}_{4}$-water system in the temperature range of 298-373 $\mathrm{K}$ and pressure range of 1-30 MPa. The axisymmetric drop shape analysis method was employed to measure the IFT between $\mathrm{CO}_{2}-\mathrm{CH}_{4}$ mixtures and brine over the temperature range from 298 to $398 \mathrm{~K}$ and the pressure range from 0.1 to $35 \mathrm{MPa} .{ }^{45}$ These studies showed that the presence of $\mathrm{CO}_{2}$ decreases the IFT of $\mathrm{CH}_{4}$-water and $\mathrm{CH}_{4}$-brine systems, while the degree of reduction depends on the mole fraction of $\mathrm{CO}_{2}\left(x_{\mathrm{CO}_{2}}\right)$ in the methane or $\mathrm{CO}_{2}$-rich phases. Furthermore, a higher salinity lead to an increase in the IFT of the $\mathrm{CO}_{2}-\mathrm{CH}_{4}$-brine system. Recently, molecular simulations and density gradient theory have been used to characterize the interfacial region of $\mathrm{CO}_{2}-\mathrm{CH}_{4}$-water system. ${ }^{37}$ Their analysis of the molecular density profiles showed that the preferential adsorption of $\mathrm{CO}_{2}$ over $\mathrm{H}_{2} \mathrm{O}$ interface is greater if compared to $\mathrm{CH}_{4}$. However, a molecular understanding of the interfacial properties of $\mathrm{CO}_{2}-\mathrm{CH}_{4}$-brine system is lacking. In this situation, we undertake the molecular dynamics (MD) simulation study of $\mathrm{CO}_{2}-\mathrm{CH}_{4}$ mixtures in the presence of brine. This interest is enhanced by the very limited amount of experimental data ${ }^{45}$ on the interfacial properties of such systems.

Our investigations showed that molecular simulations constitute a powerful tool to generally explore the chemical and surface interactions. ${ }^{46-50}$ In this work, MD simula- 
tions are performed to provide molecular-level understanding of the interfacial properties of carbon dioxide, methane, and their mixture in the presence of brine $(\mathrm{NaCl})$ under conditions relevant to $\mathrm{CO}_{2}$ sequestration. Where possible, we include explicit comparison of our results with the corresponding experimental observations. The outline of the paper is as follows: In section 2, we describe the molecular models and the details of the MD simulations. The simulation results are presented in section 3 and a brief summary as well as our conclusions can be found in section 4 .

\section{Simulation details}

All MD simulations are carried out with the LAMMPS code. ${ }^{51}$ The interactions between $\mathrm{i}$ and $\mathrm{j}$ molecular sites of different molecules are treated according to a pairwise additive Lennard-Jones (LJ) 12-6 function: ${ }^{52}$

$$
U_{\mathrm{LJ}}\left(r_{i j}\right)=4 \varepsilon_{i j}\left[\left(\frac{\sigma_{i j}}{r_{i j}}\right)^{12}-\left(\frac{\sigma_{i j}}{r_{i j}}\right)^{6}\right],
$$

where $r_{i j}$ is the distance between the centers of $i$ and $j$ sites. The parameter $\varepsilon_{i j}$ controls the strength of the short-range interactions, and the LJ diameter $\sigma_{i j}$ is used to set the length scale. The LJ parameters $\sigma_{i j}$ and $\varepsilon_{i j}$ are deduced from the conventional LorentzBerthelot combining rules:

$$
\begin{aligned}
\sigma_{i j} & =\frac{\sigma_{i}+\sigma_{j}}{2}, \\
\varepsilon_{i j} & =\sqrt{\varepsilon_{i} \varepsilon_{j}} .
\end{aligned}
$$

The charged sites are interacting with each other via the unscreened Coulomb potential

$$
U_{\text {Coul }}\left(r_{i j}\right)=\frac{q_{i} q_{j}}{4 \pi \varepsilon_{0} r_{i j}}
$$

where $q_{i}$ and $q_{j}$ are the partial charges of the sites $i$ and $j$, respectively, and $\varepsilon_{0}$ is the dielectric permittivity of vacuum. Each water molecule is represented by the rigid TIP4P/2005 model ${ }^{53}$ and $\mathrm{CO}_{2}$ is modeled using the flexible force field developed by Cygan et al. ${ }^{54}$ Methane (single-site) is represented by the TraPPE force field. ${ }^{55} \mathrm{Na}^{+}$ 
and $\mathrm{Cl}^{-}$ions are modeled using the parameters proposed by Smith and Dang. ${ }^{56}$ The LJ parameters and charges used in this study are presented in Table 1.

The simulation was initialized by placing $512 \mathrm{CO}_{2} /$ methane molecules and 2048 $\mathrm{H}_{2} \mathrm{O}$ molecules in the simulation box. In this study, we adjust the number of ions according to the salt concentration and used up to about $100 \mathrm{Na}^{+} / \mathrm{Cl}^{-}$ions. Our simulation cells are $36 \times 36 \AA$ in directions parallel to the interface and periodic boundary conditions are employed in all three spatial dimensions. The system size is sufficiently large ${ }^{40}$ to ensure that finite-size effects are negligible in our simulations (Fig. 1). Equilibration runs of $4 \mathrm{~ns}$ are performed in the NPT ensemble where the volume variations are achieved by changing only the box length in the $z$-direction $L_{z}$ (see, e.g., Fig. 2). This is followed by 2 ns production runs in the $N V E$ ensemble. Pressure is controlled by a Nosé-Hoover barostat with a relaxation time of 1 ps, and temperature is controlled by a Nosé-Hoover thermostat with a relaxation time of 0.1 ps. The use of the NVE ensemble ensures that property, such as IFT, is not biased by the extended system algorithms used to produce a constant-temperature ensemble. ${ }^{52}$ The long-range electrostatic interactions are handled using the particle-particle particle-mesh (PPPM) method with a relative error of $10^{-5}$. The bond lengths and the angles of the water molecules are constrained using the SHAKE algorithm. A cutoff radius of $L_{\min } / 2$, where $L_{\min }$ is the minimum dimension of the simulation box was applied to the LJ and Coulomb interactions. The equations of motion are integrated using a velocity Verlet algorithm with a time step of 1 fs.

The IFT is calculated from the components of the pressure tensor: ${ }^{40}$

$$
\gamma=\frac{1}{2} L_{z}\left[P_{z z}-\frac{1}{2}\left(P_{x x}+P_{y y}\right)\right]
$$

where $P_{x x}, P_{y y}$, and $P_{z z}$ are the three diagonal components of the pressure tensor along the $x^{-}, y$-, and $z$-direction, respectively, and the prefactor of $1 / 2$ accounts for the presence of two interfaces in the simulation box. Six independent trajectories each of length 6 ns per simulation are computed to achieve good statistical averages. The differences of system temperatures from the preset value during $N V E$ production runs 
were mostly negligible (typically $<1 \%$ ). The validation of our simulation model is provided in the Supporting Information (see, e.g., Figs. S1-S3).

\section{Results and discussion}

\section{1 $\mathrm{CH}_{4}-$ brine and $\mathrm{CO}_{2}-$ brine systems}

Fig. 3 provides the IFT of the $\mathrm{CH}_{4}$-brine $(\mathrm{NaCl})$ system as computed from the MD simulations (symbols) and the corresponding experimental data (smooth lines). The experimental data are taken from Kashefi et al. ${ }^{19}$ Other available experimental data $^{15-18}$ are in agreement with the ones plotted here and not included for clarity. The surface tension of water decreases from about 70 to $38 \mathrm{mN} / \mathrm{m}^{57}$ over the temperature range (311-473 K) studied here. We observe good agreement between our simulation results and the experimental data. The temperature and salt dependences of the IFT at about 7, 16, and $25 \mathrm{MPa}$ as obtained from the MD simulations are replotted in Figs. S4 and S5, respectively. The general decrease in the IFT with increasing pressure or temperature in all studied cases is consistent with other studies. ${ }^{15-23}$ Note that the IFT values of the $\mathrm{CH}_{4}$-water system displayed a moderate increase with increasing pressure at relatively high pressures. ${ }^{16,19,21}$ The minimum in the IFT was obtained at pressures around the transition point between the positive and negative relative adsorption of methane molecules. ${ }^{19,21}$ The variation of the IFT values of the $\mathrm{CH}_{4}$-brine system with pressure and temperature is similar to that observed for the corresponding $\mathrm{CH}_{4}$-water system. At a fixed temperature and pressure, our results indicate that the IFT is an increasing function of salt content in all investigated cases. The IFT values exhibit a linear correlation with the temperature and the molality of the salt solution. Notably, the resulting slopes in the former case are dependent on the pressure. For example, independent of salt concentration, the slope for the temperature dependence of IFT changes from about -0.15 to $-0.13 \mathrm{mN} /(\mathrm{m} \mathrm{K})$ in the pressure range $7-25 \mathrm{MPa}$ (see Fig. S4). We also see that, independent of temperature, the slope for the salt dependence 
of IFT is about $2.2 \mathrm{mN} /\left(\mathrm{m} \mathrm{mol} \mathrm{kg}^{-1}\right)$ in the pressure range $7-25 \mathrm{MPa}$ (see Fig. S5).

Molecular simulations can be used to compute density profiles that are not readily accessible to experimental studies. Fig. 4a shows, as an example, the density profiles of different species in the $\mathrm{CH}_{4}$-water system at $373 \mathrm{~K}$ and $16 \mathrm{MPa}$. The appearance of a maximum in the density profile of methane (dashed line) near the interface is in agreement with other studies. ${ }^{19,21-23}$ These studies have shown that the local adsorption of methane molecules which is proportional to the area under the methane peak generally decreased with increasing temperature and pressure. Furthermore, the position of the peak in the density profile of methane shifted towards the methane-rich phase with increasing pressure. The density profile of $\mathrm{H}_{2} \mathrm{O}$ (oxygen atoms) which is shown as a solid line resembles the tanh function, ${ }^{42}$ and no change was evident in this behavior with increasing temperature and pressure. ${ }^{19,21-23}$ Here the bulk density of water and methane are about 0.96 and $0.1 \mathrm{~g} / \mathrm{cm}^{3}$, respectively, in good agreement with the corresponding experimental values ${ }^{58}$ (0.97 and $0.09 \mathrm{~g} / \mathrm{cm}^{3}$, respectively). Our results indicate that the salt ions homogeneously distribute in the water-rich phase and the interfacial region is largely devoid of ions (Fig. 4b). The presence of salt hardly affects the behavior of the density profiles of various species in the $\mathrm{CH}_{4}$-water system. Notably, there is a decrease of the methane density in the water-rich phase by the addition of salt, while that of $\mathrm{H}_{2} \mathrm{O}$ in the methane-rich phase remains almost unaffected (see insets of Fig. 4). The former behavior is consistent with the decrease of the solubility of methane in the water-rich phase with salinity ${ }^{59}$ at these pressure and temperature conditions.

Fig. 5 shows the IFT of the $\mathrm{CO}_{2}$-brine $(\mathrm{NaCl})$ system as evaluated from the MD simulations (symbols) and the corresponding experimental data (smooth lines). The experimental results are obtained from the measurements of Chalbaud et al. and of Pereira et al. ${ }^{26,33}$ Other available experimental results ${ }^{15,24,25,27-32}$ are consistent with the ones plotted here and not included for clarity. The surface tension of water decreases from about 66 to $49 \mathrm{mN} / \mathrm{m}^{57}$ over the temperature range $(333-423 \mathrm{~K})$ studied here. The simulation results are in good qualitative agreement with the experimental 
data. Simulations of the surface tension of water using the TIP4P/2005 force field perform better than most of the commonly used water models, but typically underestimate the experimental data by up to $7 \mathrm{mN} / \mathrm{m}$ (see Fig. S3). In the presence of $\mathrm{CO}_{2}$, our simulated IFT values show similar deviations from the corresponding experimental data at both low and high pressures, which may be attributed to our chosen force field parameters. ${ }^{40-42}$ The temperature and salt dependences of the IFT at about 7,16 , and $25 \mathrm{MPa}$ as computed from the MD simulations are replotted in Figs. S6 and S7, respectively. The overall decrease in the IFT with increasing pressure or temperature in all investigated cases is consistent with previous reports. ${ }^{15,24-31,33-43}$ The variation of the IFT values of the $\mathrm{CO}_{2}$-brine system with pressure and temperature is similar to that obtained for the corresponding $\mathrm{CO}_{2}$-water system. At a fixed temperature and pressure, the IFT increases with increasing salt concentration in all studied cases. Generally, an exponential function is required to describe the pressure dependence on the IFT values. ${ }^{40,43}$ Moreover, these IFT values are a linear function of temperature and molality/ionic strength of the salt solution. ${ }^{26,30,33,40,41,43}$ For example, independent of salt concentration, the slope for the temperature dependence of IFT is about -0.06 $\mathrm{mN} /(\mathrm{m} \mathrm{K})$ in the pressure range $7-25 \mathrm{MPa}$ (see Fig. S6). We also find that, independent of temperature, the slope for the salt dependence of IFT is about $2 \mathrm{mN} /(\mathrm{m} \mathrm{mol}$ $\mathrm{kg}^{-1}$ ) in the pressure range 7-25 MPa (see Fig. S7), which is consistent with previous studies. ${ }^{26,42,43}$

Fig. 6a depicts the density profiles of various species in the $\mathrm{CO}_{2}$-water system at $373 \mathrm{~K}$ and $16 \mathrm{MPa}$. The density profile of $\mathrm{CO}_{2}$ (carbon atoms) which is represented as a dashed line runs through a maximum consistent with previous studies. ${ }^{24,33-43}$ These studies have shown that the local accumulation in $\mathrm{CO}_{2}$ molecules generally decreased with increasing temperature and pressure, similar to the behavior obtained for the $\mathrm{CH}_{4}$-water system. ${ }^{19,21-23}$ The position of the maximum in the density profile of $\mathrm{CO}_{2}$ also moved towards the $\mathrm{CO}_{2}$-rich phase with increasing pressure. The density profile of $\mathrm{H}_{2} \mathrm{O}$ (oxygen atoms) which is plotted as a solid line varies monotonically across the interface. No variation was observed in this behavior with increasing temperature 
and pressure. ${ }^{24,33-43}$ Here the bulk density of water and $\mathrm{CO}_{2}$ are about 0.94 and 0.4 $\mathrm{g} / \mathrm{cm}^{3}$, respectively, in good agreement with the corresponding experimental values ${ }^{58}$ (0.97 and $0.4 \mathrm{~g} / \mathrm{cm}^{3}$, respectively). The ions distribute uniformly in the water-rich phase but are repelled from the interface (Fig. 6b). Note that the density profiles indicated a positive surface excess of $\mathrm{CO}_{2}$ and a negative surface excess of ions at the interface. ${ }^{40,41}$ In the $\mathrm{CO}_{2}$-water system, values of the relative surface excess of $\mathrm{CO}_{2}$ computed from simulation and those estimated from the experimental fugacity dependence of IFT showed a non-monotonic relationship with pressure. ${ }^{40}$ It is also important to mention that, Ji et al. ${ }^{44}$ obtained strong correlation between IFT and the number density of $\mathrm{T}$ - and $\mathrm{H}$-type $\mathrm{CO}_{2}$-hydrates in the $\mathrm{CO}_{2}$-water system. The addition of salt hardly affects the behavior of the density profiles of different species in the $\mathrm{CO}_{2}$-water system. Notably, there is a decrease of the $\mathrm{CO}_{2}$ density in the waterrich phase by the addition of salt, while that of $\mathrm{H}_{2} \mathrm{O}$ in the $\mathrm{CO}_{2}$-rich phase remains almost unaffected (see insets of Fig. 6). The former behavior is consistent with the decrease of the solubility of $\mathrm{CO}_{2}$ in the water-rich phase with salinity ${ }^{41,42,60}$ at these pressure and temperature conditions.

\section{$3.2 \mathrm{CO}_{2}-\mathrm{CH}_{4}-$ brine system}

Once we have investigated the interfacial behavior of the $\mathrm{CH}_{4}$-brine and $\mathrm{CO}_{2}$-brine systems using MD simulations, the next objective is to analyze the interfacial behavior of the $\mathrm{CO}_{2}-\mathrm{CH}_{4}$-brine system. Fig. 7 shows the IFT of the $\mathrm{CO}_{2}-\mathrm{CH}_{4}-$ brine $(\mathrm{NaCl})$ system as computed from the MD simulations (symbols) and the corresponding experimental data (smooth lines). The experimental results are obtained from Liu et al. ${ }^{45}$ The surface tension of water at the temperatures studied here (348 and $398 \mathrm{~K}$ ) are about 63 and $54 \mathrm{mN} / \mathrm{m},{ }^{57}$ respectively. We observe good qualitative agreement between our simulation results and the experimental data. The dependence of the IFT on the mole fraction of carbon dioxide $x_{\mathrm{CO}_{2}}$ at about 7, 16, and $25 \mathrm{MPa}$ as obtained from the MD simulations is replotted in Fig. S8. As expected, the IFT values generally decrease with increasing pressure or temperature in all studied cases. The 
presence of $\mathrm{CO}_{2}$ decreases the IFT values of the $\mathrm{CH}_{4}$-water and $\mathrm{CH}_{4}$-brine systems, while the degree of reduction depends on the amount of $\mathrm{CO}_{2}$ in each sample. These IFT values display a linear correlation with the mole fraction of carbon dioxide $x_{\mathrm{CO}_{2}}$, and the resulting slopes are dependent on temperature and pressure. For example, independent of salt concentration, the slope for $x_{\mathrm{CO}_{2}}$ dependence of IFT changes from about -13 to $-17 \mathrm{mN} / \mathrm{m}$ at $348 \mathrm{~K}$ and in the pressure range $7-25 \mathrm{MPa}$ (see Fig. S8). The corresponding change in the slope is from about -9 to $-14 \mathrm{mN} / \mathrm{m}$ at $398 \mathrm{~K}$. Furthermore, at a fixed temperature and pressure, our results here show that the IFT values increase with increasing salt concentration in all investigated cases.

Fig. 8a displays the density profiles of different species in the $\mathrm{CO}_{2}-\mathrm{CH}_{4}$-water $\left(x_{\mathrm{CO}_{2}} \approx 0.6\right)$ system at $348 \mathrm{~K}$ and $16 \mathrm{MPa}$. The density profile of each species presents the same trend as discussed before. Notably, the density profiles of $\mathrm{CO}_{2}$ (carbon atoms) and $\mathrm{CH}_{4}$ which are plotted as dashed and dotted lines, respectively, show adsorption peaks located at the interface with relatively high intensity for the former. The density profile of $\mathrm{H}_{2} \mathrm{O}$ (oxygen atoms) which is depicted as a solid line changes monotonically across the interface. The preferential adsorption of $\mathrm{CO}_{2}$ over $\mathrm{CH}_{4}$ indicates that water molecules are more likely to interact with $\mathrm{CO}_{2}$. These results are consistent with previous reports. ${ }^{37}$ Also, the ions distribute evenly in the water-rich phase, but move away from the interface (Fig. 8b). Our simulation results show that the presence of salt hardly affects the behavior of the density profiles of various species in the $\mathrm{CO}_{2}-\mathrm{CH}_{4}$-water system. We point out that both $\mathrm{CO}_{2}$ and methane densities in the water-rich phase decrease with increasing salt concentration, while that of $\mathrm{H}_{2} \mathrm{O}$ in the methane- or $\mathrm{CO}_{2}$-rich phase remains almost uninfluenced (see insets of Fig. 8). Such variations will be further discussed below. Additionally, Figs. S9-S13 consider these simulated density profiles at other conditions. As before, we observe that the local adsorption of $\mathrm{CO}_{2}$ and methane molecules generally decrease with increasing temperature and pressure in all cases. Furthermore, the position of the peaks in the density profiles of $\mathrm{CO}_{2}$ and methane shift towards the water-poor region with increasing pressure. The monotonic behavior of the density profile of $\mathrm{H}_{2} \mathrm{O}$ is not affected with 
increasing temperature and pressure. $\mathrm{No} \mathrm{NaCl}$ is found in the methane- or $\mathrm{CO}_{2}$-rich phases in all studied cases.

The knowledge of, e.g., the concentration of $\mathrm{H}_{2} \mathrm{O}$ dissolved in $\mathrm{CO}_{2}-\mathrm{CH}_{4}$ mixture can help develop rational injection strategies to maximize geological $\mathrm{CO}_{2}$ sequestration and natural gas production. ${ }^{1,3,5-7,48-50}$ Fig. 9 presents the mole fractions of the different species in the $\mathrm{CO}_{2}-\mathrm{CH}_{4}$-water system at $323 \mathrm{~K}$ and $9 \mathrm{MPa}$, as computed from the MD simulations (symbols) and the corresponding experimental data (smooth lines). The experimental results are obtained from different studies. ${ }^{8,61,62}$ We observe good agreement between our simulation results and the experimental data. The agreement is better for the mole fractions of methane $\left(y_{\mathrm{CH}_{4}}\right)$ and $\mathrm{CO}_{2}\left(y_{\mathrm{CO}_{2}}\right)$ in the water-rich phase. The mole fraction of water $\left(x_{\mathrm{H}_{2} \mathrm{O}}\right)$ in the methane- or $\mathrm{CO}_{2}$-rich phase is, however, a factor of up to 2 lower than the corresponding experimental value. The mole fraction of methane in the water-rich phase decreases with increasing $x_{\mathrm{CO}_{2}}$, while that of $\mathrm{CO}_{2}$ steeply increases. This steep rise is expected, given that $\mathrm{CO}_{2}$ interacts more strongly with $\mathrm{H}_{2} \mathrm{O}$ than methane. Initially the mole fraction of water $x_{\mathrm{H}_{2} \mathrm{O}}$ increases almost linearly with $x_{\mathrm{CO}_{2}}$. However, this increase is steeper at high values of $x_{\mathrm{CO}_{2}}$, possibly because of the relatively strong quadrupole-dipole interactions between $\mathrm{CO}_{2}$ and $\mathrm{H}_{2} \mathrm{O}$.

Additionally, Figs. S14-S16 consider our results for these mole fractions at other conditions. Both methane and $\mathrm{CO}_{2}$ mole fractions in the water-rich phase increase with increasing pressure, while that of water $x_{\mathrm{H}_{2} \mathrm{O}}$ shows the opposite behavior. All these mole fractions, except for $\mathrm{H}_{2} \mathrm{O}$, show no significant variation with temperature. With all other conditions the same, the mole fraction of water increases with temperature. Notably, the mole fractions of methane and $\mathrm{CO}_{2}$ in the water-rich phase decrease with increasing salt concentration (salting-out effect), while that of water $x_{\mathrm{H}_{2} \mathrm{O}}$ remains almost unaffected in all studied cases. Loring et al. ${ }^{8}$ performed in situ high-pressure infrared spectroscopic titrations to quantify the solubility of $\mathrm{H}_{2} \mathrm{O}$ in $\mathrm{CO}_{2}-\mathrm{CH}_{4}$ mixture at reservoir conditions of $323 \mathrm{~K}$ and $9 \mathrm{MPa}$. They employed different thermodynamic models which accurately predicted the amount of dissolved $\mathrm{H}_{2} \mathrm{O}$ concentrations at saturation in $\mathrm{CO}_{2}-\mathrm{CH}_{4}$ mixture. Therefore, these theoretical models employing the 
same parameters as for the $\mathrm{CO}_{2}-\mathrm{CH}_{4}$-water system could be applied to predict the corresponding water solubility in the presence of salt. We also used orientational distribution functions to look into the the arrangement of molecules at the interface in the $\mathrm{CO}_{2}-\mathrm{CH}_{4}$-water and $\mathrm{CO}_{2}-\mathrm{CH}_{4}$-brine systems (Figs. S17-S22). The orientation angle $\theta$ is measured for both the dipole vector and the $\mathrm{H}-\mathrm{H}$ vector of $\mathrm{H}_{2} \mathrm{O}$, and the head-to-tail vector of $\mathrm{CO}_{2}$ molecule relative to the axis perpendicular to the interface. The results show that $\mathrm{CO}_{2}$ molecules tend to arrange in parallel to the interface as in the pure case. ${ }^{39}$ In the case of water, the orientation of the vectors at the interface is not random when compared to the the bulk water phase $((1 / 2) \sin \theta)$. However, we find no obvious effect of salinity on the orientations of $\mathrm{CO}_{2}$ or water molecules at the interface.

As an aside, we note that prior simulations have examined region of the phase diagram of such systems at which three phases coexist. ${ }^{37}$ The temperature and pressure conditions selected for our MD simulations encompass the range of values relevant to geologic carbon sequestration. We expect that these studies could provide more insight into the rational design of practical $\mathrm{CO}_{2}$ sequestration processes in deep saline aquifers, which involves surface wetting and migration of supercritical $\mathrm{CO}_{2}$ through the cap rock. A knowledge of the dissolved $\mathrm{H}_{2} \mathrm{O}$ concentrations in $\mathrm{CO}_{2}-\mathrm{CH}_{4}$ mixtures can be beneficial for the enhanced gas recovery processes in shales. Further improvement of the quality of predictions using molecular simulations may result from including, e.g., other choices of water model. The choice of force field parameters employed here is in a similar spirit to that used in recent simulation studies of interfacial behavior of $\mathrm{CO}_{2}-\mathrm{CH}_{4}$-water system. ${ }^{37} \mathrm{Fig}$. S23 shows simulation results obtained by replacing TIP4P/2005 water model with flexible F3C water model ${ }^{39,43}$ for the $\mathrm{CO}_{2}-\mathrm{CH}_{4}$-brine system, and poor results are obtained. The Exp-6 models for the $\mathrm{CO}_{2}$-water system gave accurate estimate of solubilities for both water- and $\mathrm{CO}_{2}$-rich phases with optimized cross interaction parameters. ${ }^{63}$ However, the Exp-6 water model is inaccurate for the prediction of thermodynamic properties of brine. ${ }^{64}$ Furthermore, using polarizable force fields and accounting explicitly for strong directional interactions between 
$\mathrm{H}_{2} \mathrm{O}$ and $\mathrm{CO}_{2}$ molecules, improved predictions are obtained. ${ }^{65}$ In the future, we plan to study the effects of cross interaction parameters, polarizable models etc. on the interfacial properties of $\mathrm{CO}_{2}-\mathrm{CH}_{4}$-brine system. It is also worthwhile to further study the effect of ion type and chemical reactions such as carbonate formation on the phase behavior of these mixtures.

\subsection{Conclusions}

In this work, molecular dynamics simulations have been performed to study $\mathrm{CO}_{2}$, methane, and their mixture in the presence of brine over a broad range of temperature (311-473 K), pressure (up to about $100 \mathrm{MPa}$ ), and $\mathrm{NaCl}$ concentration (up to about $14 \mathrm{wt} \%$ ). We find that the temperature, pressure, and salt concentration dependence of the interfacial tension predicted by our model is in agreement with experiments in all studied systems. The general decrease in the IFT values of the $\mathrm{CH}_{4}$-brine system with pressure and temperature is similar to that observed for the corresponding $\mathrm{CH}_{4}$-water system. The IFT of methane and brine is a linearly increasing function of salt content, and the resulting slopes are dependent on the pressure. We also show that the local adsorption of methane molecules generally decrease with increasing temperature and pressure. The presence of salt hardly affects the behavior of the density profiles of different species in the $\mathrm{CH}_{4}$-water system.

A similar behavior as methane is obtained for such systems containing $\mathrm{CO}_{2}$ and $\mathrm{CO}_{2}-\mathrm{CH}_{4}$ mixture. The IFT of $\mathrm{CO}_{2}$ and brine increases linearly with increasing salinity, however, the resulting slopes are independent of pressure. The presence of $\mathrm{CO}_{2}$ decreases the IFT values of the $\mathrm{CH}_{4}$-water and $\mathrm{CH}_{4}$-brine systems, while the degree of reduction depends on the amount of $\mathrm{CO}_{2}$ in each sample. We find that these IFT values show a linear correlation with the mole fraction of carbon dioxide $x_{\mathrm{CO}_{2}}$, and the resulting slopes are dependent on temperature and pressure. Here, the density profiles of $\mathrm{CO}_{2}$ and $\mathrm{CH}_{4}$ show adsorption peaks located at the interface with relatively high intensity for the former. The preferential adsorption of $\mathrm{CO}_{2}$ over $\mathrm{CH}_{4}$ indicates that water molecules are more likely to associate with $\mathrm{CO}_{2}$ by virtue of strong 
quadrupole-dipole interactions.

The knowledge of, e.g., the concentration of $\mathrm{H}_{2} \mathrm{O}$ dissolved in $\mathrm{CO}_{2}-\mathrm{CH}_{4}$ mixture can help develop rational injection strategies to optimize geological $\mathrm{CO}_{2}$ sequestration and natural gas production. The simulation results for the mole fractions of the various species in the $\mathrm{CO}_{2}-\mathrm{CH}_{4}$-water system at $323 \mathrm{~K}$ and $9 \mathrm{MPa}$ are consistent with experiments. We demonstrate that the mole fractions of methane and $\mathrm{CO}_{2}$ in the water-rich phase decrease with increasing salt concentration, while that of $\mathrm{H}_{2} \mathrm{O}$ in the methane- or $\mathrm{CO}_{2}$-rich phases remains almost unaffected in all studied cases. Therefore, theoretical

models ${ }^{8}$ employing the same parameters as for the $\mathrm{CO}_{2}-\mathrm{CH}_{4}$-water system could be used to predict the corresponding water solubility in the presence of salt. We believe that the above mentioned properties will be relevant to geological carbon storage and $\mathrm{CO}_{2}$ enhanced shale gas production.

\section{Acknowledgments}

The research reported in this publication was supported by funding from King Abdullah University of Science and Technology (KAUST), Kingdom of Saudi Arabia. Y. Y. and A. K. N. N. gratefully acknowledge computational facilities provided at KAUST.

\section{Supporting Information}

Additional details of simulation analysis are provided in the Supporting Information. 


\section{References}

(1) Busch, A.; Alles, S.; Gensterblum, Y.; Prinz, D.; Dewhurst, D. N.; Raven, M. D.; Stanjek, H.; Krooss, B. M. Carbon Dioxide Storage Potential of Shales. Int. J. Greenhouse Gas Control 2008, 2, 297-308.

(2) Gaus, I. Role and Impact of $\mathrm{CO}_{2}$-rock Interactions during $\mathrm{CO}_{2}$ Storage in Sedimentary Rocks. Int. J. Greenhouse Gas Control 2010, 4, 73-89.

(3) Romanov, V. N. Evidence of Irreversible $\mathrm{CO}_{2}$ Intercalation in Montmorillonite. Int. J. Greenhouse Gas Control 2013, 81, 220-226.

(4) Edwards, R. W.; Celia, M. A.; Bandilla, K. W.; Doster, F.; Kanno, C. M. A Model to Estimate Carbon Dioxide Injectivity and Storage Capacity for Geological Sequestration in Shale Gas Wells. Environ. Sci. Technol. 2015, 49, 9222-9229.

(5) Schaef, H. T.; Loring, J. S.; Glezakou, V. A.; Miller, Q. R.; Chen, J.; Owen, A. T.; Lee, M. S.; Ilton, E. S.; Felmy, A. R.; McGrail, B. P.; Thompson, C. J. Competitive Sorption of $\mathrm{CO}_{2}$ and $\mathrm{H}_{2} \mathrm{O}$ in 2:1 Layer Phyllosilicates. Geochim. Cosmochim. Acta 2015, 161, 248-257.

(6) Liu, D.; Yuan, P.; Liu, H.; Li, T.; Tan, D.; Yuan, W.; He, H. High-pressure Adsorption of Methane on Montmorillonite, Kaolinite and Illite. Appl. Clay Sci. 2013, 85, 25-30.

(7) Yang, F.; Xie, C.; Ning, Z.; Krooss, B.M. High-Pressure Methane Sorption on Dry and Moisture-Equilibrated Shales. Energy Fuels 2017, 31 (1), 482-492.

(8) Loring, J. S.; Bacon, D. H.; Springer, R. D.; Anderko, A.; Gopinath, S.; Yonkofski, C. M.; Thompson, C. J.; McGrail, B. P.; Rosso, K. M.; Schaef, H. T. Water Solubility at Saturation for $\mathrm{CO}_{2}-\mathrm{CH}_{4}$ Mixtures at $323.2 \mathrm{~K}$ and $9.000 \mathrm{MPa}$. J. Chem. Eng. Data 2017, 62, 1608-1614. 
(9) Li, Z.; Dong, M.; Li, S.; Huang, S. $\mathrm{CO}_{2}$ Sequestration in Depleted Oil and Gas Reservoirs-Caprock Characterization and Storage Capacity. Energy Convers. Manage. 2006, 47 (11), 1372-1382.

(10) Espinoza, D.N.; Santamarina, J.C. Water-CO $\mathrm{CO}_{2}-$ Mineral Systems: Interfacial Tension, Contact Angle, and Diffusion-Implications to $\mathrm{CO}_{2}$ Geological Storage. Water Resour. Res. 2010, 46, W07537.

(11) Sun, C.Y.; Chen, G.J. Measurement of Interfacial Tension for the $\mathrm{CO}_{2}$ Injected Crude Oil + Reservoir Water System. J. Chem. Eng. Data 2005, 50 (3), 936-938.

(12) Jaeger, P.T.; Alotaibi, M.B.; Nasr-El-Din, H.A. Influence of Compressed Carbon Dioxide on the Capillarity of the Gas-Crude Oil-Reservoir Water System. J. Chem. Eng. Data 2010, 55 (11), 5246-5251.

(13) Eastoe, J.; Cazelles, B. M. H.; Steytler, D. C.; Holmes, J. D.; Pitt, A. R.; Wear, J. T.; Heenan, R. K. Water-in-CO $\mathrm{CO}_{2}$ Microemulsions Studied by Small-Angle Neutron Scattering. Langmuir 1997, 13, 6980-6984.

(14) da Rocha, S. R. P.; Johnston, K. P. Interfacial Thermodynamics of Surfactants at the $\mathrm{CO}_{2}$-Water Interface. Langmuir 2000, 16, 3690-3695.

(15) Jho, C.; Nealon, D.; Shogbola, S.; King, A. D. J. Effect of Pressure on the Surface Tension of Water: Adsorption of Hydrocarbon Gases and Carbon Dioxide on Water at Temperatures between 0 and $50{ }^{\circ} \mathrm{C}$. J. Colloid Interface Sci. 1978, 65, 141-154.

(16) Wiegand, G.; Franck, E. U. Interfacial Tension between Water and Non-Polar Fluids up to $473 \mathrm{~K}$ and 2800 bar. Ber. Bunsenges. Phys. Chem. 1994, 98, 809817.

(17) Sachs, W.; Meyn, V. Pressure and Temperature Dependence of the Surface Tension in the System Natural Gas/Water. Principles of Investigation and the First 
Precise Experimental Data for Pure Methane/Water at $25^{\circ} \mathrm{C}$ up to $46.8 \mathrm{MPa}$. Colloids Surf., A 1995, 94, 291-301.

(18) Ren, Q. Y.; Chen, G. J.; Yan, W.; Guo, T. M. Interfacial Tension of $\left(\mathrm{CO}_{2}+\right.$ $\left.\mathrm{CH}_{4}\right)+$ Water from $298 \mathrm{~K}$ to $373 \mathrm{~K}$ and Pressures up to $30 \mathrm{MPa}$. J. Chem. Eng. Data 2000, 45, 610-612.

(19) Kashefi, K.; Pereira, L.M.; Chapoy, A.; Burgass, R.; Tohidi, B. Measurement and Modelling of Interfacial Tension in Methane/Water and Methane/Brine Systems at Reservoir Conditions. Fluid Phase Equilib. 2016, 409, 301-311.

(20) Schmidt, K. A. G.; Folas, G. K.; Kvamme, B. Calculation of the Interfacial Tension of the Methane-Water System with the Linear Gradient Theory. Fluid Phase Equilib. 2007, 261, 230-237.

(21) Miqueu, C.; Miguez, J.M.; Pineiro, M.M.; Lafitte, T.; Mendiboure, B. Simultaneous Application of the Gradient Theory and Monte Carlo Molecular Simulation for the Investigation of Methane/Water Interfacial Properties. J. Phys. Chem. B 2011, 115, 9618-9625.

(22) Biscay, F.; Ghoufi, A.; Lachet, V.; Malfreyt, P. Monte Carlo Calculation of the Methane-Water Interfacial Tension at High Pressures. J. Chem. Phys. 2009, 131, 124707.

(23) Sakamaki, R.; Sum, A.K.; Narumi, T.; Ohmura, R.; Yasuoka, K. Thermodynamic Properties of Methane/Water Interface Predicted by Molecular Dynamics Simulations. J. Chem. Phys. 2011, 134, 144702.

(24) Kvamme, B.; Kuznetsova, T.; Hebach, A.; Oberhof, A.; Lunde, E. Measurements and Modelling of Interfacial Tension for Water + Carbon Dioxide Systems at Elevated Pressures. Comput. Mater. Sci. 2007, 38, 506-513.

(25) Bachu, S.; Bennion, D. B. Interfacial Tension Between $\mathrm{CO}_{2}$, Freshwater, and Brine in the Range of Pressure from (2 to 27) MPa, Temperature from (20 to 
125) ${ }^{\circ} \mathrm{C}$, and Water Salinity from (0 to 334000) $\mathrm{mg} \mathrm{L}^{-1}$. J. Chem. Eng. Data 2009, $54,765-775$.

(26) Chalbaud, C.; Robin, M.; Lombard, J. M.; Martin, F.; Egermann, P.; Bertin, H. Interfacial Tension Measurements and Wettability Evaluation for Geological $\mathrm{CO}_{2}$ Storage. Adv. Water Resour. 2009, 32, 98-109.

(27) Georgiadis, A.; Maitland, G.; Trusler, J.M.; Bismarck, A. Interfacial Tension Measurements of the $\left(\mathrm{H}_{2} \mathrm{O}+\mathrm{CO}_{2}\right)$ System at Elevated Pressures and Temperatures. J. Chem. Eng. Data 2010, 55, 4168-4175.

(28) Georgiadis, A.; Llovell, F.; Bismarck, A.; Blas, F. J.; Galindo, A.; Maitland, G. C.; Trusler, J. P. M.; Jackson, G. Interfacial Tension Measurements and Modelling of (Carbon Dioxide + n-Alkane) and (Carbon Dioxide + Water) Binary Mixtures at Elevated Pressures and Temperatures. J. Supercrit. Fluids 2010, 55, 743-754.

(29) Aggelopoulos, C. A.; Robin, M.; Vizika, O. Interfacial Tension between $\mathrm{CO}_{2}$ and Brine $\left(\mathrm{NaCl}+\mathrm{CaCl}_{2}\right)$ at Elevated Pressures and Temperatures: the Additive Effect of Different Salts. Adv. Water Resour. 2011, 34, 505-511.

(30) Li, X.; Boek, E. S.; Maitland, G. C.; Trusler, J. P. M. Interfacial Tension of (Brines $\left.+\mathrm{CO}_{2}\right)$ : $\mathrm{CaCl}_{2}(\mathrm{aq}), \mathrm{MgCl}_{2}(\mathrm{aq})$, and $\mathrm{Na}_{2} \mathrm{SO}_{4}(\mathrm{aq})$ at Temperatures between (343 and 423$) \mathrm{K}$, Pressures between (2 and 50) MPa, and Molalities of (0.5 to 5) mol $\mathrm{kg}^{-1}$. J. Chem. Eng. Data 2012, 57, 1369-1375.

(31) Pereira, L. M.; Chapoy, A.; Burgass, R.; Oliveira, M. B.; Coutinho, J. A.; Tohidi, B. Study of the Impact of High Temperatures and Pressures on the Equilibrium Densities and Interfacial Tension of the Carbon Dioxide/Water System. J. Chem. Thermodyn. 2016, 93, 404-415.

(32) Liu, Y.; Tang, J.; Wang, M.; Wang, Q.; Tong, J.; Zhao, J.; Song, Y. Measurement of Interfacial Tension of $\mathrm{CO}_{2}$ and $\mathrm{NaCl}$ Aqueous Solution over Wide Temperature, Pressure, and Salinity Ranges. J. Chem. Eng. Data 2017, 62 (3), 1036-1046. 
(33) Pereira, L. M.; Chapoy, A.; Burgass, R.; Tohidi, B. Interfacial Tension of $\mathrm{CO}_{2}$ + Brine Systems: Experiments and Predictive Modelling. Adv. Water Resour. 2017, 103, 64-75.

(34) Li, X.-S.; Liu, J. M.; Fu, D. Investigation of Interfacial Tensions for Carbon Dioxide Aqueous Solutions by Perturbed-Chain Statistical Associating Fluid Theory Combined with Density-Gradient Theory. Ind. Eng. Chem. Res. 2008, 47, 89118917.

(35) Lafitte, T.; Mendiboure, B.; Pineiro, M. M.; Bessieres, D.; Miqueu, C. Interfacial Properties of Water $/ \mathrm{CO}_{2}$ : a Comprehensive Description through a Gradient Theory-SAFT-VR Mie Approach. J. Phys. Chem. B 2010, 114, 11110-11116.

(36) Hu, J.; Chen, J.; Mi, J. Prediction of Interfacial Structure and Tension of Binary Mixtures Containing Carbon Dioxide. Ind. Eng. Chem. Res. 2012, 51, 1236-1243.

(37) Miguez, J. M.; Garrido, J. M.; Blas, F.J.; Segura, H.; Meja, A.; Pineiro, M. M. Comprehensive Characterization of Interfacial Behavior for the Mixture $\mathrm{CO}_{2}+$ $\mathrm{H}_{2} \mathrm{O}+\mathrm{CH}_{4}$ : Comparison between Atomistic and Coarse Grained Molecular Simulation Models and Density Gradient Theory. J. Phys. Chem. C 2014, 118 (42), 24504-24519.

(38) da Rocha, S. R. P.; Johnston, K. P.; Westacott, R. E.; Rossky, P. J. Molecular Structure of the Water-Supercritical $\mathrm{CO}_{2}$ Interface. J. Phys. Chem. B 2001, 105, 12092-12104.

(39) Zhao, L.; Lin, S.; Mendenhall, J. D.; Yuet, P. K.; Blankschtein, D. Molecular Dynamics Investigation of the Various Atomic Force Contributions to the Interfacial Tension at the Supercritical $\mathrm{CO}_{2}$-water Interface. J. Phys. Chem. B 2011, 115, 6076-6087.

(40) Nielsen, L. C.; Bourg, I. C.; Sposito, G. Predicting $\mathrm{CO}_{2}$-Water Interfacial Tension 
under Pressure and Temperature Conditions of Geologic $\mathrm{CO}_{2}$ Storage. Geochim. Cosmochim. Acta 2012, 81, 28-38.

(41) Li, X.; Ross, D. A.; Trusler, J. P.; Maitland, G. C.; Boek, E. S. Molecular Dynamics Simulations of $\mathrm{CO}_{2}$ and Brine Interfacial Tension at High Temperatures and Pressures. J. Phys. Chem. B 2013, 117, 5647-5652.

(42) Liu, Y.; Lafitte, T.; Panagiotopoulos, A.; Debenedetti, P. Simulations of VaporLiquid Phase Equilibrium and Interfacial Tension in the $\mathrm{CO}_{2}-\mathrm{H}_{2} \mathrm{O}-\mathrm{NaCl}$ System. AIChE J. 2013, 59, 35143522.

(43) Zhao, L.; Ji, J.; Tao, L.; Lin, S. Ionic Effects on Supercritical $\mathrm{CO}_{2}$-Brine Interfacial Tensions: Molecular Dynamics Simulations and a Universal Correlation with Ionic Strength, Temperature, and Pressure. Langmuir 2016, 32, 9188-9196.

(44) Ji, J.; Zhao, L.; Tao, L.; Lin, S. Molecular Gibbs Surface Excess and $\mathrm{CO}_{2^{-}}$ Hydrate Density Determine the Strong Temperature-and Pressure-Dependent Supercritical $\mathrm{CO}_{2}$-Brine Interfacial Tension. J. Phys. Chem. B 2017, DOI: 10.1021/acs.jpcb.7b03320.

(45) Liu, Y.; Li, H.A.; Okuno, R. Measurements and Modeling of Interfacial Tension for $\mathrm{CO}_{2} / \mathrm{CH}_{4} /$ Brine Systems under Reservoir Conditions. Ind. Eng. Chem. Res. 2016, 55, 12358-12375.

(46) Kumar, N.A.; Seidel, C. Polyelectrolyte Brushes with Added Salt. Macromolecules 2005, 38 (22), 9341-9350.

(47) Nair, A.K.N.; Uyaver, S.; Sun, S. Conformational Transitions of a Weak Polyampholyte. J. Chem. Phys. 2014, 141 (13), 134905.

(48) Kadoura, A.; Nair, A. K. N.; Sun, S. Adsorption of Carbon Dioxide, Methane, and Their Mixture by Montmorillonite in the Presence of Water. Microporous Mesoporous Mater. 2016, 225, 331-341. 
(49) Kadoura, A.; Nair, A. K. N.; Sun, S. Molecular Dynamics Simulations of Carbon Dioxide, Methane, and Their Mixture in Montmorillonite Clay Hydrates J. Phys. Chem. C 2016, 120, 1251712529.

(50) Kadoura, A.; Nair, A. K. N.; Sun, S. Molecular Simulation Study of Montmorillonite in Contact with Variably Wet Supercritical Carbon Dioxide. J. Phys. Chem. C 2017, 121, 61996208.

(51) Plimpton, S. Fast Parallel Algorithms for Short-Range Molecular Dynamics. J. Comput. Phys. 1995, 117, 1-19.

(52) Frenkel, D.; Smit, B. Understanding Molecular Simulation: From Algorithms to Applications; Academic Press: London, 2002.

(53) Abascal, J. L. F.; Vega, C. A General Purpose Model for the Condensed Phases of Water: TIP4P/2005 J. Chem. Phys. 2005, 123, 234505.

(54) Cygan, R. T.; Romanov, V. N.; Myshakin, E. M. Molecular Simulation of Carbon Dioxide Capture by Montmorillonite Using an Accurate and Flexible Force Field. J. Phys. Chem. C 2012, 116 (24), 13079-13091.

(55) Martin, M. G.; Siepmann, J. I. Transferable Potentials for Phase Equilibria. 1. United-Atom Description of n-Alkanes. J. Phys. Chem. B 1998, 102, 2569-2577.

(56) Smith, D. E.; Dang, L. X. Computer Simulations of NaCl Association in Polarizable Water. J. Chem. Phys. 1994, 100, 3757.

(57) Vargaftik, N. B.; Volkov, B. N.; Voljak, L. D. International Tables of the Surface Tension of Water. J. Phys. Chem. Ref. Data 1983, 12, 817820.

(58) NIST Chemistry WebBook. http://webbook.nist.gov/chemistry/fluid.

(59) Duan, Z., Mller, N., Greenberg, J. and Weare, J.H. The Prediction of Methane Solubility in Natural Waters to High Ionic Strength from 0 to $250{ }^{\circ} \mathrm{C}$ and from 0 to 1600 bar. Geochim. Cosmochim. Acta 1992, 56 (4), 1451-1460. 
(60) Duan, Z.; Sun, R. An Improved Model Calculating $\mathrm{CO}_{2}$ Solubility in Pure Water and Aqueous $\mathrm{NaCl}$ Solutions from 273 to $533 \mathrm{~K}$ and from 0 to 2000 bar. Chem. Geol. 2003, 193, 257-271.

(61) Al Ghafri, S. Z.; Forte, E.; Maitland, G. C.; Rodriguez-Henrquez, J. J.; Trusler, J. M. Experimental and Modeling Study of the Phase Behavior of (Methane+ $\mathrm{CO}_{2}+$ Water) Mixtures. J. Phys. Chem. B 2014, 118, 14461-14478.

(62) Frost, M.; Karakatsani, E.; von Solms, N.; Richon, D.; Kontogeorgis, G. M. Vapor-Liquid Equilibrium of Methane with Water and Methanol. Measurements and Modeling. J. Chem. Eng. Data 2013, 59, 961-967.

(63) Orozco, G. A.; Economou, I. G.; Panagiotopoulos, A. Z. Optimization of Intermolecular Potential Parameters for the $\mathrm{CO}_{2} / \mathrm{H}_{2} \mathrm{O}$ Mixture. J. Phys. Chem. B 2014, 118, 11504-11511.

(64) Orozco, G. A.; Moultos, O. A.; Jiang, H.; Economou, I. G.; Panagiotopoulos, A. Z. Molecular Simulation of Thermodynamic and Transport Properties for the $\mathrm{H}_{2} \mathrm{O}+\mathrm{NaCl}$ System. J. Chem. Phys. 2014, 141, 234507.

(65) Jiang, H.; Economou, I. G.; Panagiotopoulos, A. Z. Phase Equilibria of Water $/ \mathrm{CO}_{2}$ and Water/n-Alkane Mixtures from Polarizable Models. J. Phys. Chem. B 2017, 121, 1386-1395. 
Table 1: Charges $q$ and LJ parameters $\sigma$ and $\varepsilon$ of water, methane, $\mathrm{CO}_{2}$, and ions.

\begin{tabular}{lrrr}
\hline Force or charge site & $\sigma(\AA)$ & $\varepsilon(\mathrm{kcal} / \mathrm{mol})$ & $q(\mathrm{e})$ \\
\hline Water (TIP4P/2005 model) ${ }^{53}$ & & & \\
O & 3.1589 & 0.1852 & 0.5564 \\
$\mathrm{H}$ & & & -1.1128 \\
$\mathrm{M}$ & & & \\
& & & \\
Methane (TraPPE model) $^{55}$ & & & \\
$\mathrm{C}$ & 3.7300 & 0.2941 & \\
& & & 0.6512 \\
Carbon dioxide (flexible Cygan model) $^{54}$ & & & -0.3256 \\
$\mathrm{C}$ & 2.8000 & 0.0559 & \\
O & 3.0280 & 0.1597 & \\
& & & 1.0000 \\
Ions $^{56}$ & & & -1.0000 \\
$\mathrm{Na}$ & 2.3500 & 0.1300 & \\
Cl & 4.4000 & 0.1000 & \\
\hline
\end{tabular}




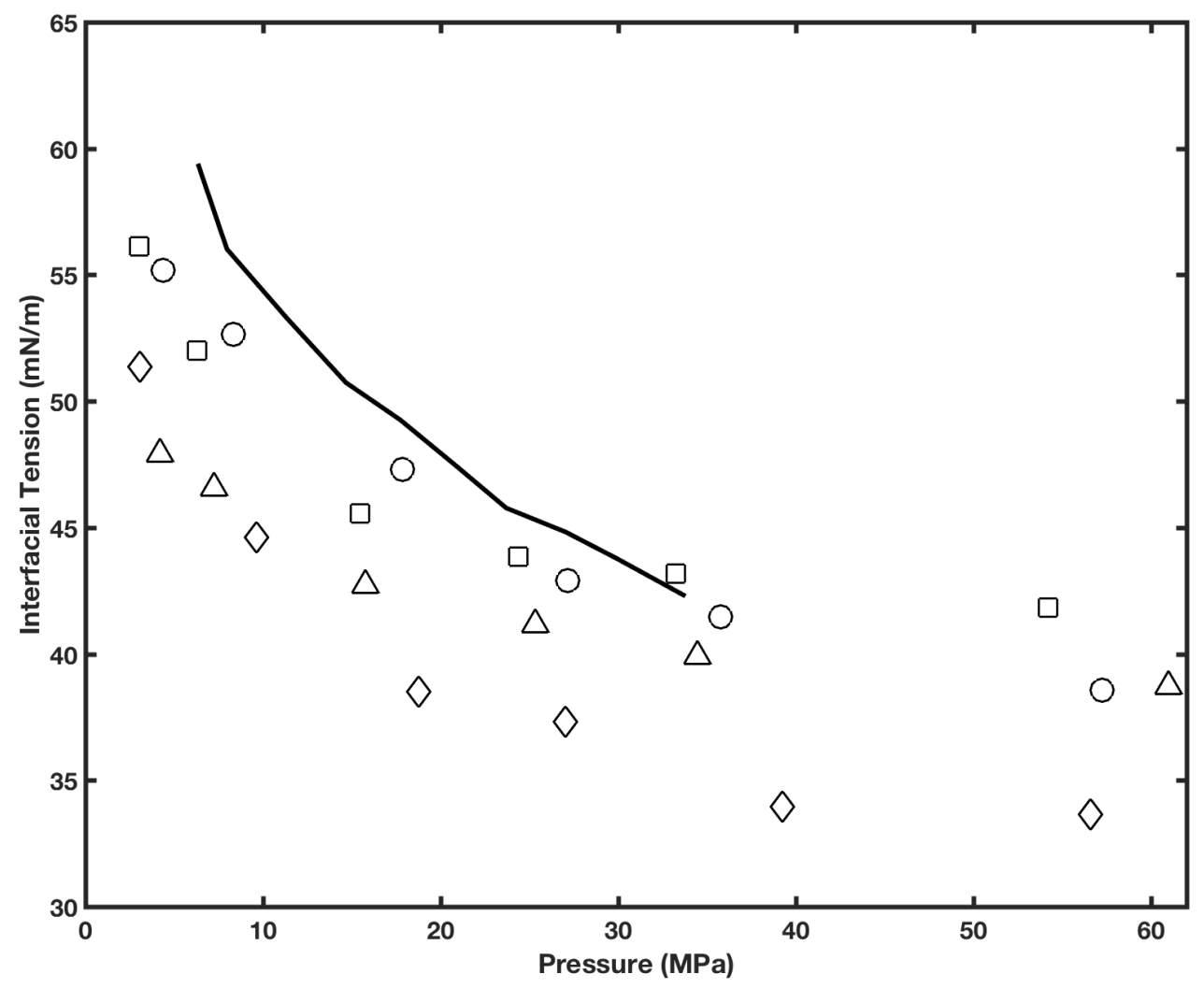

Figure 1: Pressure dependence of IFT for the $\mathrm{CO}_{2}-\mathrm{CH}_{4}-$ brine system $\left(x_{\mathrm{CO}_{2}} \approx 0.6\right.$, 10 wt $\% \mathrm{NaCl}$ ) at $348 \mathrm{~K}$. Shown are the results obtained from the MD simulations (symbols) and the corresponding experimental data ${ }^{45}$ (solid line). Number of water molecules/number of $\mathrm{CO}_{2}+\mathrm{CH}_{4}$ molecules: 4096/1024 (circles), 2048/512 (squares), 1024/256 (diamonds), and 512/128 (triangles). 

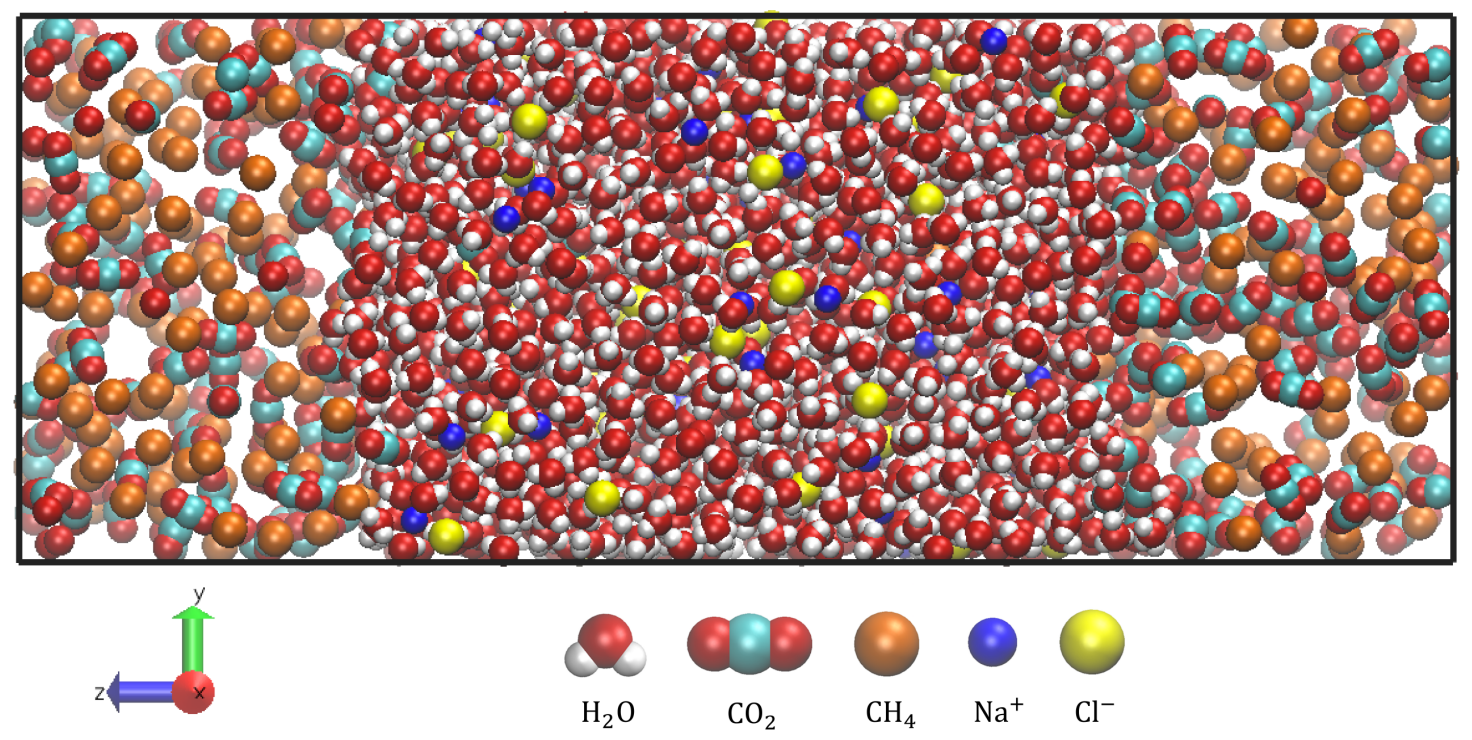

Figure 2: Equilibrium snapshot of $\mathrm{CO}_{2}-\mathrm{CH}_{4}$-brine system $\left(x_{\mathrm{CO}_{2}} \approx 0.6,10 \mathrm{wt} \%\right.$ $\mathrm{NaCl})$ at $T=348 \mathrm{~K}$ and a pressure of $25 \mathrm{MPa}$. 
(a)

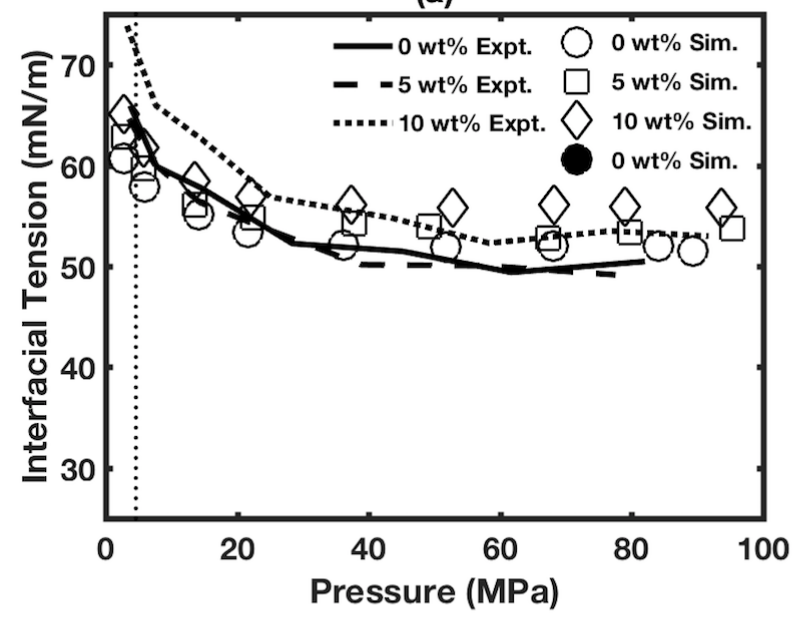

(c)

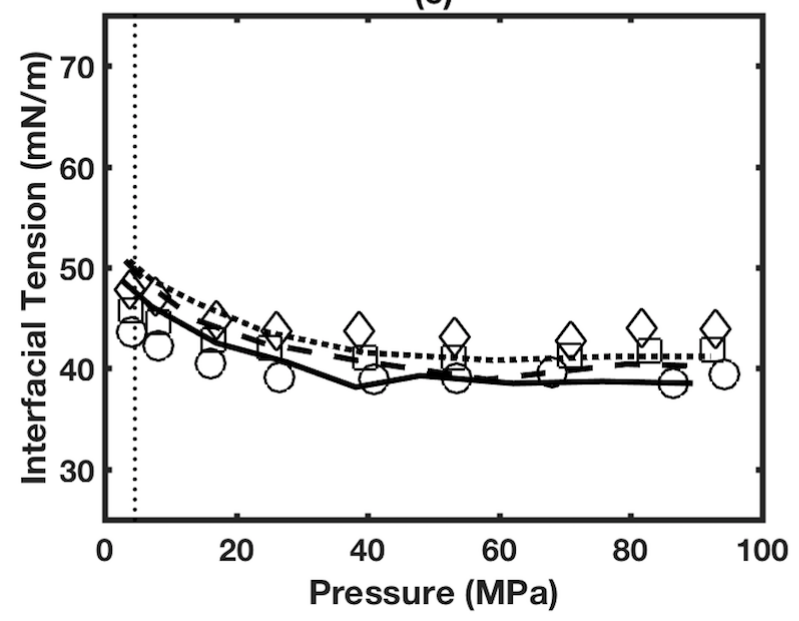

(b)

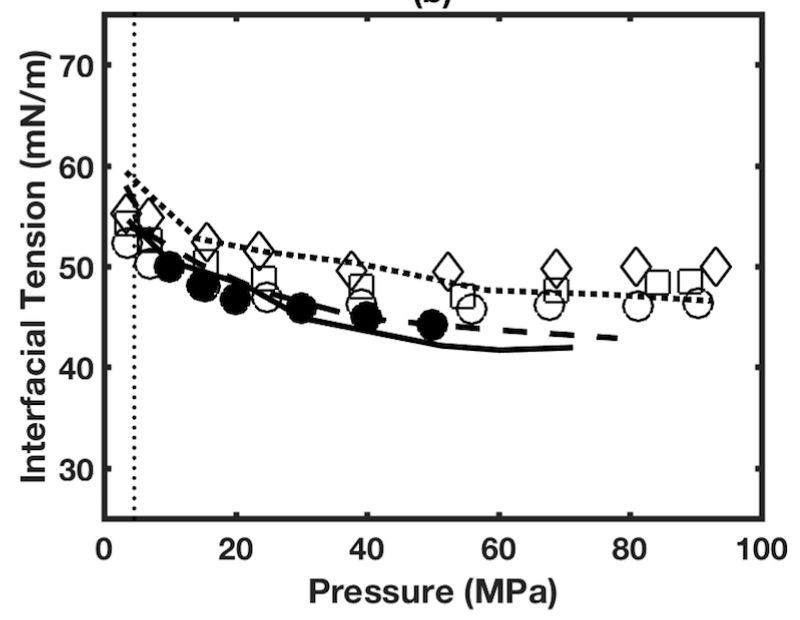

(d)

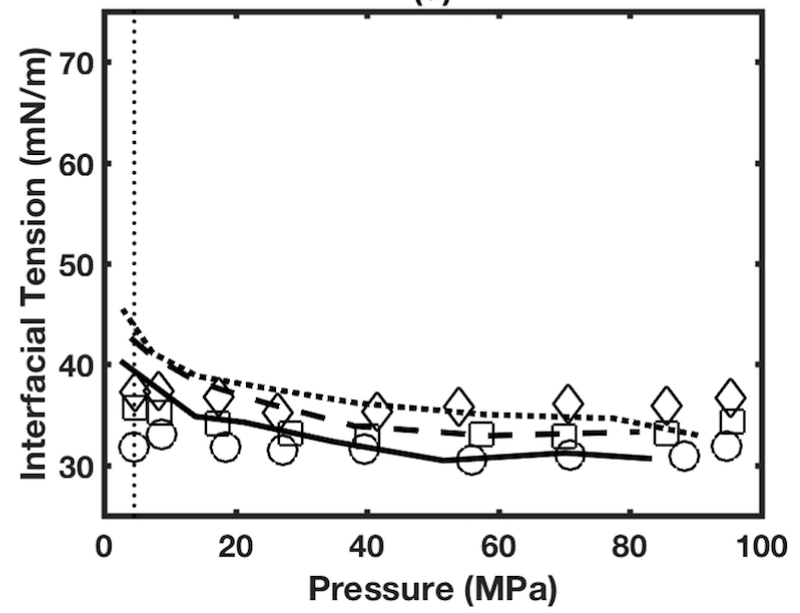

Figure 3: Pressure dependence of IFT for the $\mathrm{CH}_{4}$-water and $\mathrm{CH}_{4}$-brine systems, as computed from our MD simulations (open symbols) and the corresponding experimental data ${ }^{19}$ (smooth lines): (a) 311, (b) 373, (c) 423, and (d) $473 \mathrm{~K}$. Error bars are smaller than the symbol size. Simulation data of Biscay et al. ${ }^{22}$ are shown as solid symbols. 

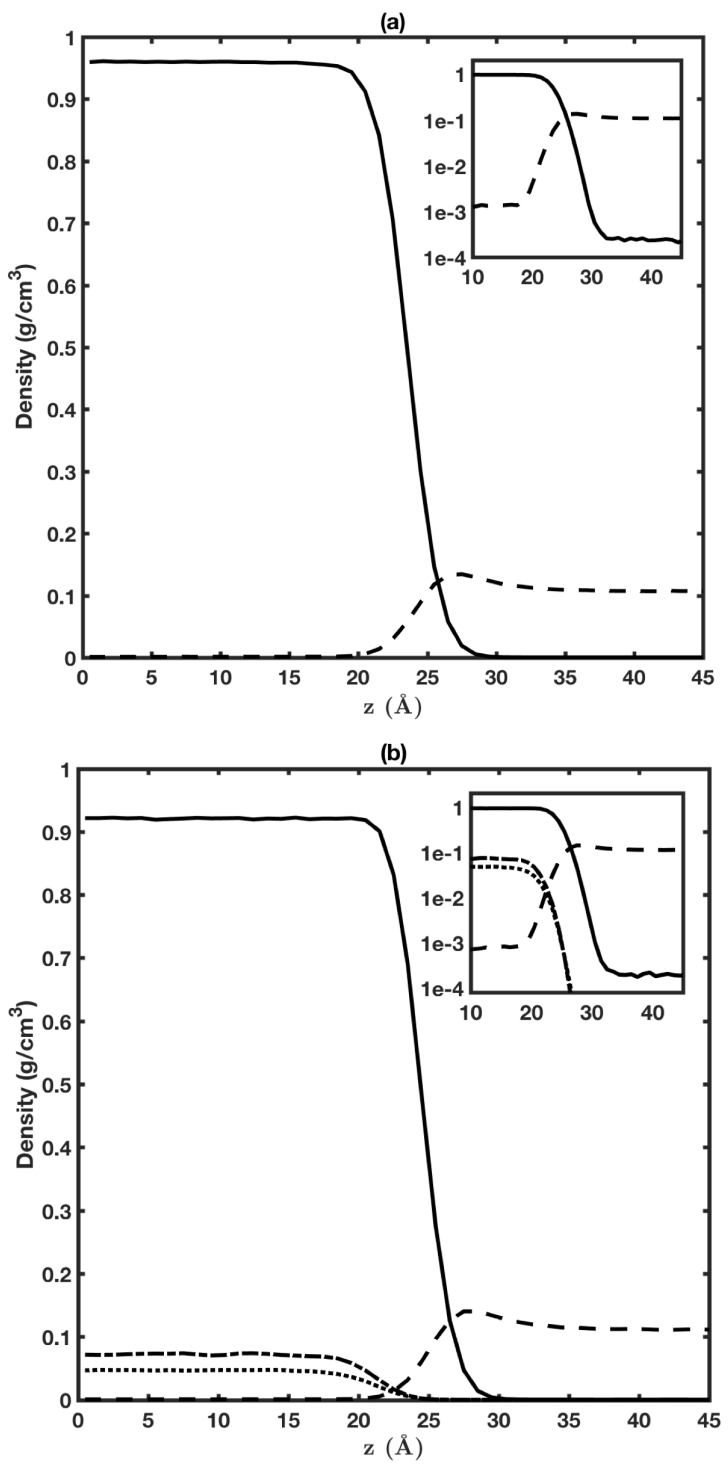

Figure 4: Equilibrium distributions of different species in the (a) $\mathrm{CH}_{4}$-water and (b) $\mathrm{CH}_{4}$-brine $(10 \mathrm{wt} \% \mathrm{NaCl}$ ) systems at $373 \mathrm{~K}$ and $16 \mathrm{MPa}$. Solid, dashed, dotted, and dot-dashed lines represent $\mathrm{H}_{2} \mathrm{O}$ (oxygen atoms), methane, $\mathrm{Na}^{+}$, and $\mathrm{Cl}^{-}$, respectively. 
(a)

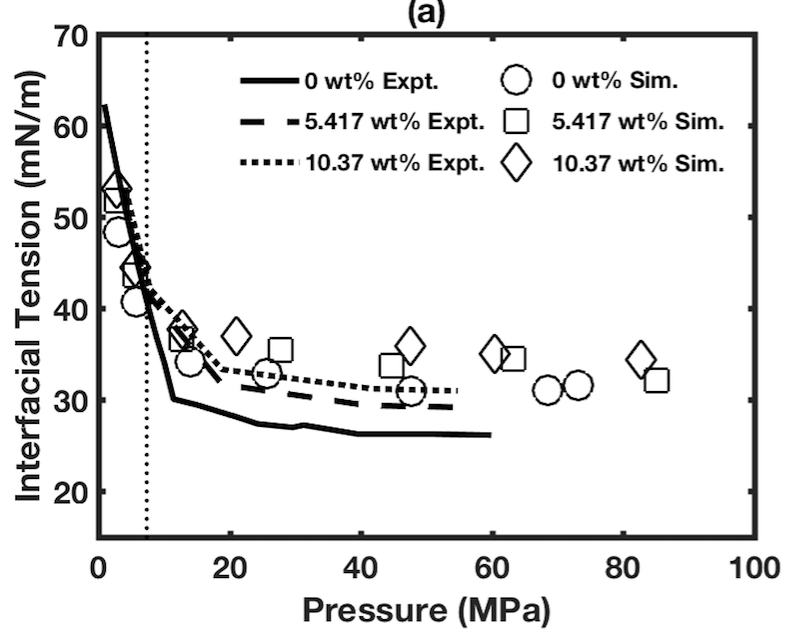

(c)

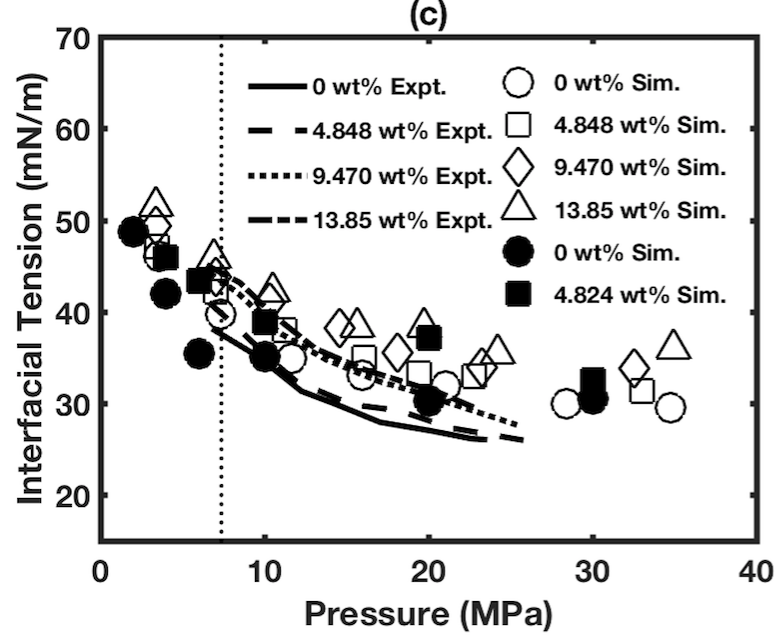

(b)

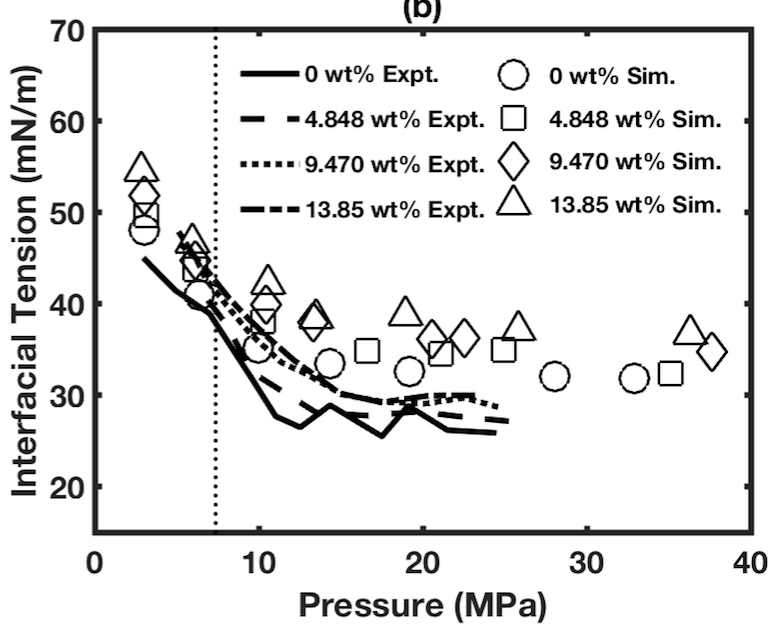

(d)

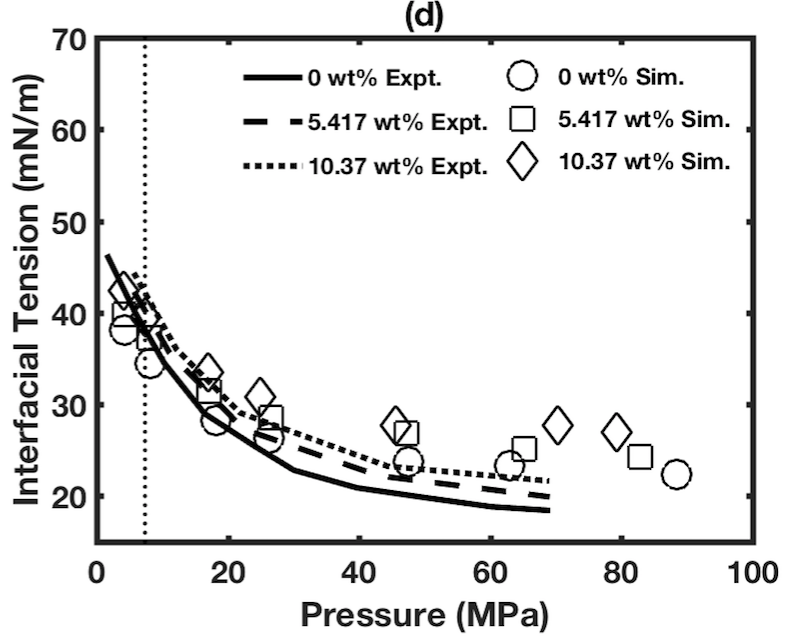

Figure 5: Pressure dependence of IFT for the $\mathrm{CO}_{2}$-water and $\mathrm{CO}_{2}$-brine systems, as computed from our MD simulations (open symbols) and the corresponding experimental data ${ }^{26,33}$ (smooth lines): (a) 333, (b) 344, (c) 373, and (d) 423 K. Error bars are smaller than the symbol size. Simulation data of Li et al. ${ }^{41}$ are shown as solid symbols. 

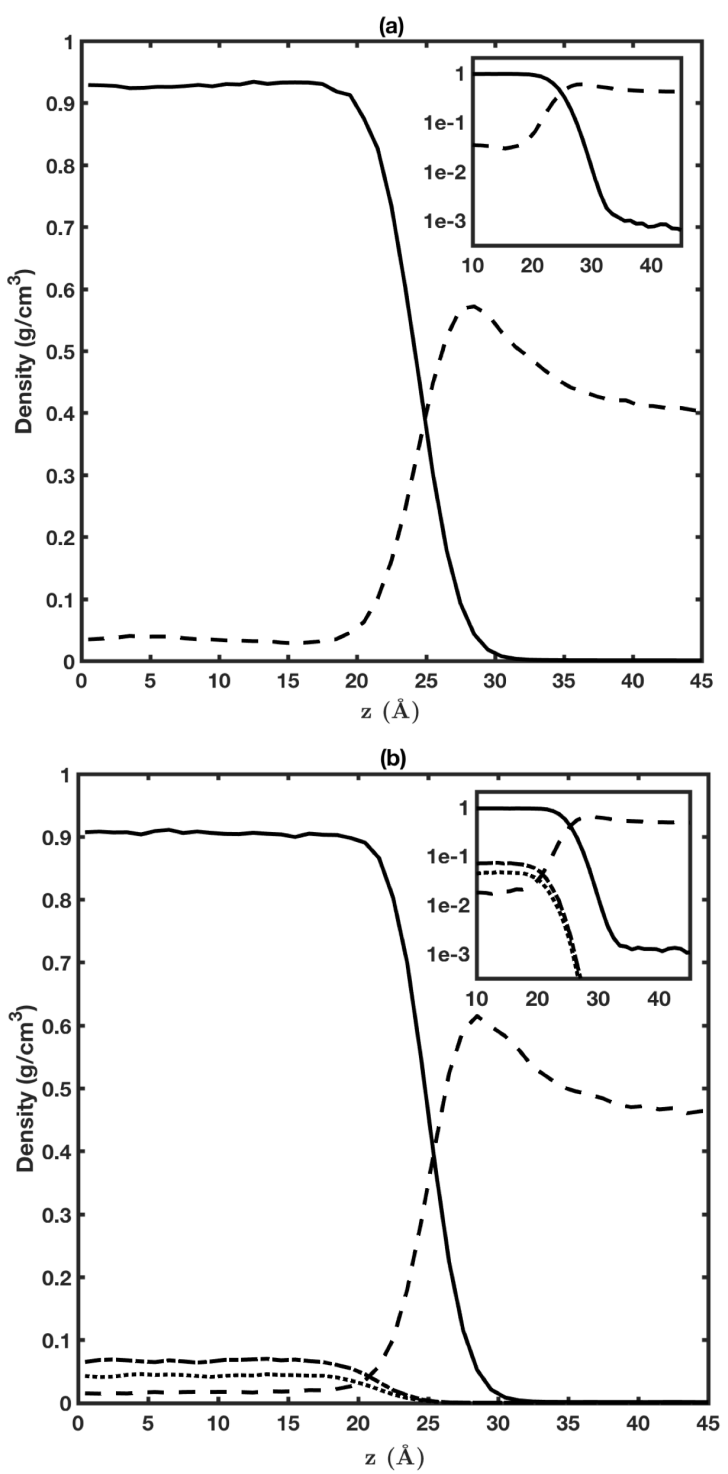

Figure 6: Equilibrium distributions of different species in the (a) $\mathrm{CO}_{2}$-water and (b) $\mathrm{CO}_{2}$-brine $(10 \mathrm{wt} \% \mathrm{NaCl})$ systems at $373 \mathrm{~K}$ and $16 \mathrm{MPa}$. Solid, dashed, dotted, and dot-dashed lines represent $\mathrm{H}_{2} \mathrm{O}$ (oxygen atoms), $\mathrm{CO}_{2}$ (carbon atoms), $\mathrm{Na}^{+}$, and $\mathrm{Cl}^{-}$, respectively. 

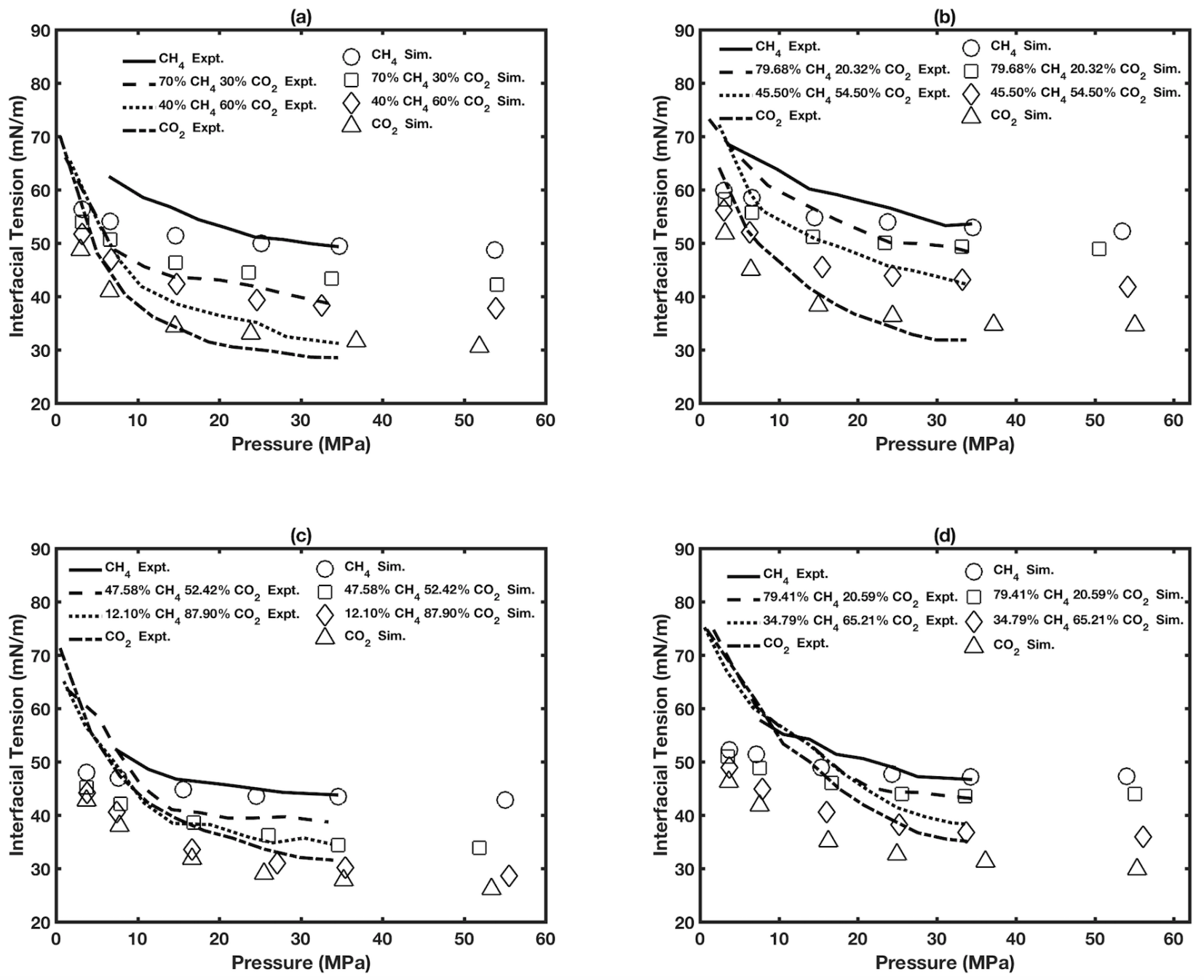

Figure 7: Pressure dependence of IFT for the $\mathrm{CO}_{2}-\mathrm{CH}_{4}-$ water (left panels) system and the $\mathrm{CO}_{2}-\mathrm{CH}_{4}-$ brine (right panels) system with $10 \mathrm{wt} \% \mathrm{NaCl}$. Shown are the results obtained from the MD simulations (symbols) and the corresponding experimental data $^{45}$ (smooth lines) at 348 (top panels) and $398 \mathrm{~K}$ (bottom panels). Error bars are smaller than the symbol size. 

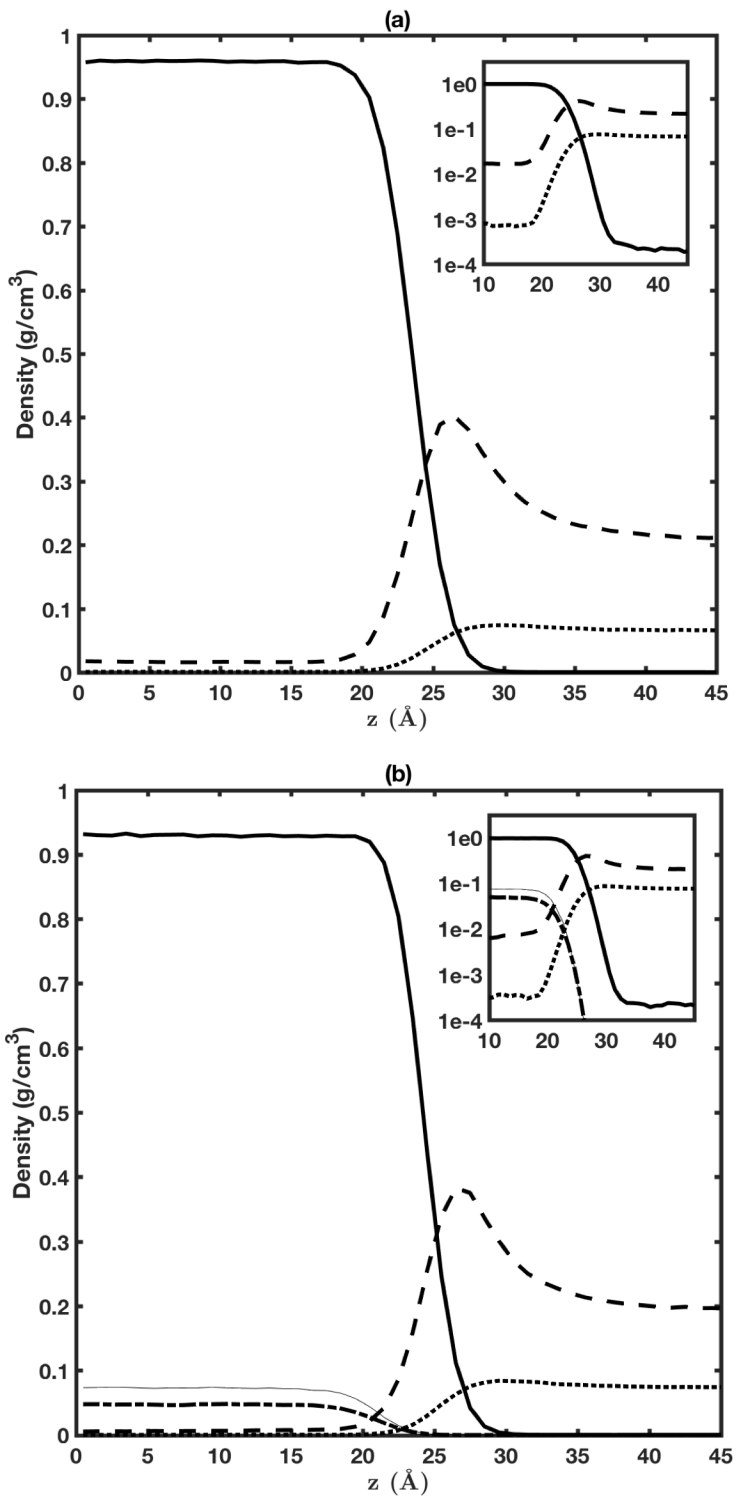

Figure 8: Equilibrium distributions of different species in the (a) $\mathrm{CO}_{2}-\mathrm{CH}_{4}$-water and (b) $\mathrm{CO}_{2}-\mathrm{CH}_{4}$-brine $(10 \mathrm{wt} \% \mathrm{NaCl}$ ) systems at $348 \mathrm{~K}$ and $16 \mathrm{MPa}$. The mole fraction of $\mathrm{CO}_{2} x_{\mathrm{CO}_{2}} \approx 0.6$. Thick solid, dashed, dotted, dot-dashed, and thin solid lines represent $\mathrm{H}_{2} \mathrm{O}$ (oxygen atoms), $\mathrm{CO}_{2}$ (carbon atoms), methane, $\mathrm{Na}^{+}$, and $\mathrm{Cl}^{-}$, respectively. 


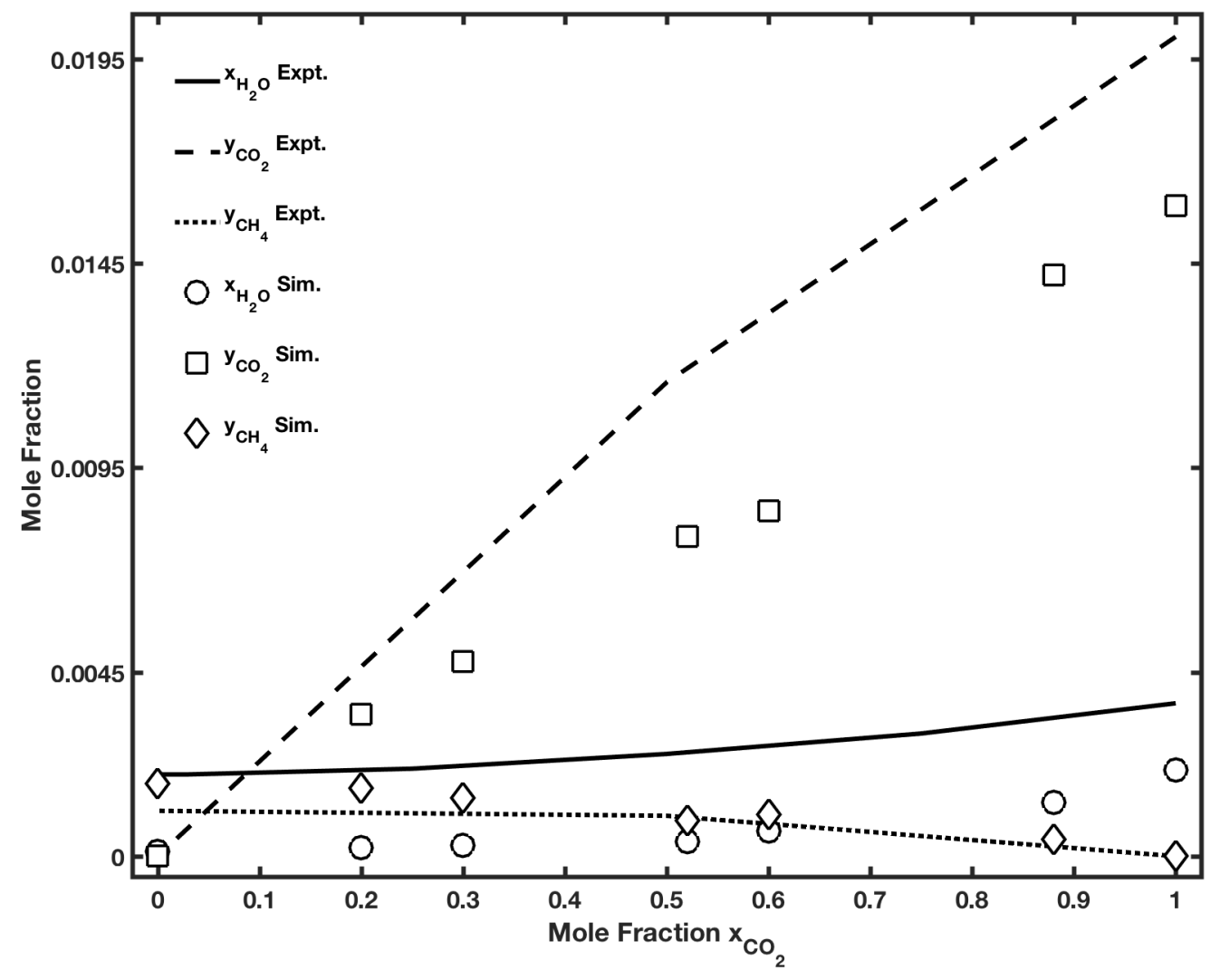

Figure 9: The mole fractions of the different species in the $\mathrm{CO}_{2}-\mathrm{CH}_{4}$-water system as a function of the mole fraction of $\mathrm{CO}_{2}$ in the methane or $\mathrm{CO}_{2}$-rich phase at $323 \mathrm{~K}$ and $9 \mathrm{MPa}$. Shown are the results obtained from the MD simulations (symbols) and the corresponding experimental data ${ }^{8,61,62}$ (smooth lines). The simulation uncertainties are comparable with the symbol size. 

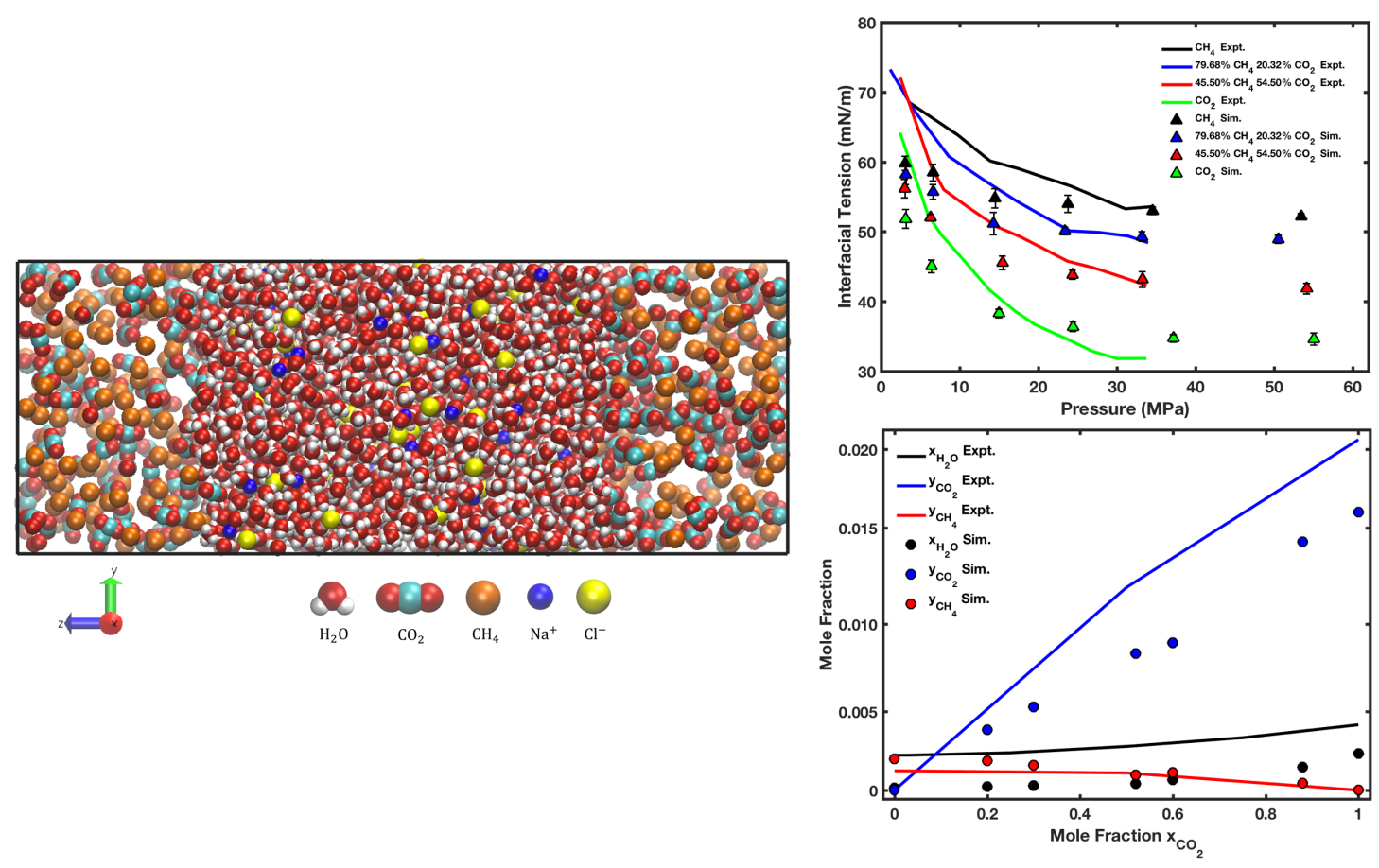

TOC Graphic 